\title{
RANCANG BANGUN PENAMPIL PARAMETER CUACA BERBASIS PERSONAL COMPUTER UNTUK STASIUN CUACA MINI
}

\author{
Arif Wicaksono $^{1}$, Rudy Gunawan ${ }^{2}$ \\ 1,2Program Studi Teknik Elektro, Fakultas Teknik \\ Universitas Sangga Buana \\ rudy.gunawan@usbypkp.ac.id
}

\begin{abstract}
ABSTRAK
Tujuan dari perancangan alat penampil parameter cuaca berbasis personal computer untuk stasiun cuaca mini ini adalah agar terciptanya alat yang dapat menampilkan keadaan cuaca secara online dan dapat disimpan dalam sebuah databese. Alat ini menggunakan komunikasi serial RS232 sebagai alat komunikasi data dari hasil pemantauan cuaca yang diterima oleh mikrokontroler AVR ATMega8535. Pada bagian perangkat keras modul data yang dikirimkan oleh komunikasi serial RS232 akan diproses dengan menggunakan program Visual Basic 6.0 agar dapat ditampilkan pada personal computer sehigga menjadi sebuah informasi yang dapat menjadi acuan untuk berbagai bidang misalnya bidang transportasi udara, pelayaran, pertanian, komunikasi dan lain-lain.
\end{abstract}

Kata Kunci: Personal computer, Komunikasi serial RS232, Mikrokontroler, Visual Basic.

\section{PENDAHULUAN}

Salah satu faktor penting dalam kehidupan manusia adalah keadaan alam, dimana salah satu aktivitas alam adalah cuaca. Keadaan cuaca sangat berpengaruh dalam kehidupan manusia. Dan tidak dapat dipungkiri manusia memiliki faktor human error dalam memonitoring cuaca secara terusmenerus. Pengamatan cuaca ditempat diharapkan dapat dilakukan setiap saat dalam waktu yang singkat. Stasiun pengamat cuaca biasanya berada dilokasi yang jauh dari jangkauan pengamat. Sehingga untuk melakukan pengamatan diperlukan waktu tertentu untuk mengamatinya.

Keadaan cuaca sangat berpengaruh dalam mengatur masalah transportasi terutama transportasi udara dan laut. Selain itu dapat digunakan dalam bidang pertanian sebagai informasi masa bercocok tanam, dalam bidang komunikasi sebagai acuan bahwa keadaan cuaca menentukan baik tidaknya sinyal komunikasi pada waktu-waktu tertentu. Oleh karena itu diperlukan sistem monitoring cuaca yang akurat dan lebih mudah dioperasikan.
Maka untuk memenuhi kebutuhan akan sistim pengukuran elemen iklim dan cuaca yang otomatis, murah dan akurat serta dari kemampuan pertimbangan mikrokontroler, dalam penelitian ini penulis ingin mengimplementasikan sebuah stasiun cuaca yang di kendalikan oleh mikrokontroller AVR ATmega8535 dan komputer sebagai penampil informasi cuaca.

\section{TEORI PENUNJANG}

\section{Sensor}

Sebenarnya sensor secara umum didefinisikan sebagai alat yang mampu menangkap fenomena fisika atau kimia kemudian mengubahnya menjadi sinyal listrik baik arus listrik ataupun tegangan[1].

\section{Komunikasi Serial RS232}

Standar komunikasi serial untuk komputer ialah $R S-232$, mempunyai standar tegangan yang berbeda dengan serial port mikrokontroller. Kecepatan transfer data RS232 cukup rendah, kecepatan maksimal hanya 19200 bits/detik. Pengiriman data dilakukan secara bit per bit, kecepatan transfer 
data harus sama antara pengirim dan penerima. Kecepatan transmisi transfer data sering disebut dengan baudrate. Baudrate yang umum dipakai adalah 300, 600, 1200, 2400, 9600, dsb (bit/detik). Panjang data bit yang sering digunakan diantaranya adalah 4, 5, 6, 7, dan 8 bit.

Format transmisi satu byte pada RS232 Data yang ditransmisikan pada format diatas adalah 8 bit, sebelum data tersebut ditransmisikan maka akan diawali oleh start bit dengan logik 0 (0 Volt), kemudian 8 bit data dan diakhiri oleh satu stop bit dengan logika 1 (5 Volt).

\section{Definisi Mikrokontroler AVR}

Mikrokontroler adalah suatu IC (Integrated Circuit) dengan kepadatan yang sangat tinggi, dimana semua bagian yang diperlukan untuk suatu kontroler sudah dikemas dalam satu keping[2]. Mikrokontroler biasanya terdiri atas :

1. Central Processing Unit (CPU),

2. Random Access Memory (RAM),

3. EEPROM/EPROM/PRO/ROM,

4. Input/Output (I/O),

5. Timer

6. Interupt Controller

Mikrokontroler adalah salah satu bagian dasar dari suatu sistem komputer. Meskipun mempunyai bentuk yang jauh lebih kecil dari suatu komputer pribadi dan komputer mainframe, mikrokontroler dibangun dari elemen-elemen dasar yang sama.

\section{Komunikasi Serial pada ATMega8535}

Peralatan komunikasi Serial pada ATmega8535 sudah terintegrasi pada system Chip. Dan masing-masing registernya baik data maupun kontrol dihubungkan dengan register Input-Output atau Port, sebagaimana peralatan lainnya. Sehingga User (kita) cukup hanya mengakses register-register yang berhubungan dengan Serial inilah untuk mempengaruhi atau memanipulasi peralatan tersebut. Pada prisipnya register-register peralatan ini hanya 5 buah. UDR, UCSRA, UCSRB, UCSRC, dan UBRR.

\section{Visual Basic 6.0}

Visual Basic diciptakan pada tahun 1991 oleh Microsoft untuk menggantikan bahasa pemrograman BASIC (Beginner's Allpurpose Symbolic Instruction Code)[3]. Visual Basic pada dasarnya adalah sebuah bahasa pemrograman komputer. Bahasa pemrograman adalah perintah-perintah atau instruksi yang dimengerti oleh komputer untuk melakukan tugas tertentu. (Arief Ramadhan. 2004. Microsoft Visual Basic 6.0)

Visual Basic merupakan suatu bahasa pemrograman yang sangat mudah dimengerti dan dipahami sehingga lebih banyak yang memilih pemrograman Visual Basic pada saat ini. Visual Basic atau sering disebut VB selain disebut sebagai bahasa pemrograman, juga disebut sebagai sarana (tool) untuk menghasilkan program aplikasi berbasis Windows.

\section{Database}

Basis data (database) merupakan kumpulan data yang saling berhubungan satu dengan yang lainnya, disimpan diperangkat keras komputer dan digunakan perangkat lunak untuk memanipulasinya. Database merupakan salah satu komponen yang penting dalam sistem informasi merupakan basis dalam menyediakan informasi bagi para pemakai. Penerapan basis data dalam sistem informasi disebut dengan database sistem.

\section{PERANCANGAN}

\section{Prinsip-Prinsip Perancangan Sistem}

Untuk membuat sebuah program perangkat lunak antar muka untuk inisialisasi dan tampilan data maka langkah awalnya adalah melakukan analisasi sistem. Langkah selanjutnya membangun perangkat lunak dari hasil analisis sistem tadi, menjadi sebuah perangkat lunak yang siap untuk hubungkan ke Rancang Bangun Penampil Parameter Cuaca berbasis Personal Computer untuk Stasiun Cuaca Mini.

Adapun perancangan program perangkat lunak antar muka untuk inisialisasi dan tampilan pemantauan cuaca ini meliputi flow map, contex diagram (CD) dan data flow diagram (DFD). Gambar 3.1 menjelaskan tentang flow map diagram dimana pada flowmap tersebut menjelaskan tentang alur dari aliran data fisik, entitas yang terlibat dan 
kegiatan oprasi yang ber hubungan dengan aplikasi.

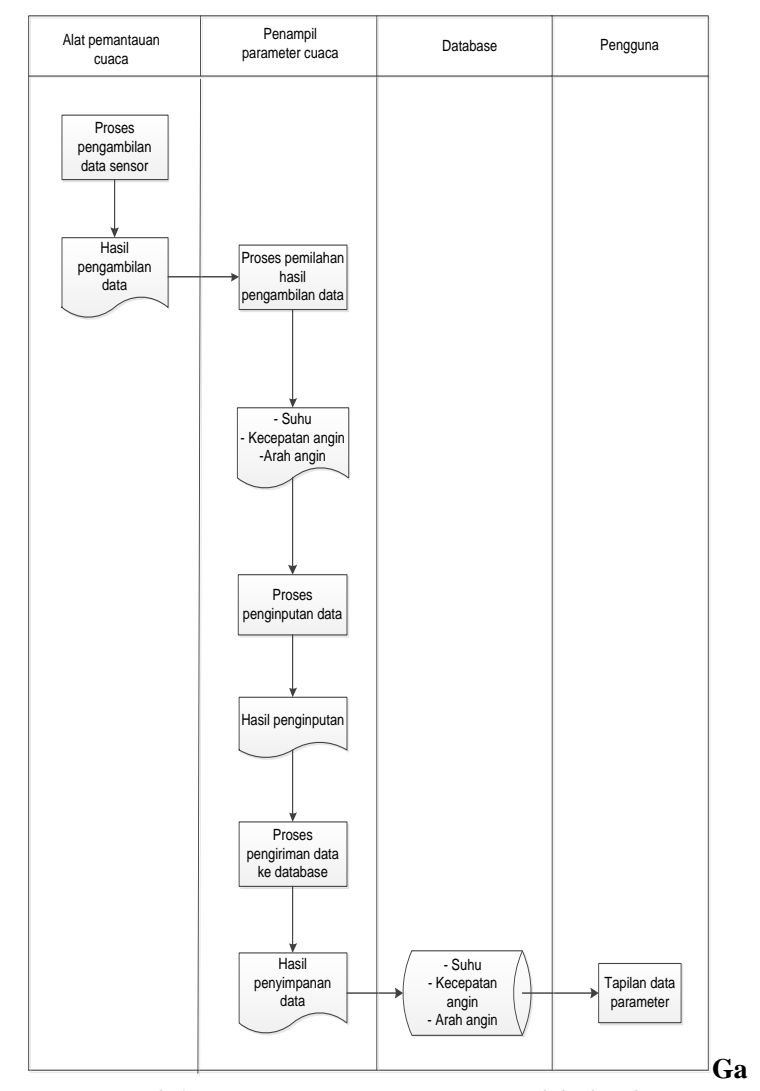

mbar 3.1 Flow Map untuk Program Inisialisasi dan Tampilan Parameter Pemantauan Cuaca

Prinsip-prinsip yang digunakan dalam merancang sebuah perangkat lunak antar muka adalah sebagai berikut :

1. Merefleksikan model mental pengguna, artinya model mental berasal dari kombinasi pengalaman dunia nyata, pengalaman dari software lain dan penggunaan komputer secara umum.

2. Explicit and Implicid action, artinya memberikan petunjuk dan kesan visual untuk memanipulasi objek.

3. Direct manipulation, artinya pengguna akan mendapatkan dampaknya dengan segera setelah melakukan aksi.

4. User control, artinya mengijinkan pengguna untuk mengontrol dan menginisialisasiaksi aksi dengan menampilkan beberapa level kontrol.

5. Feedback and communication, artinya adanya suatu pesan yang muncul jika terjadi kesalahan sehingga tidak membingungkan pengguna.

6. Consistency, artinya harus ada konsostensi pada antar muka yang dibuat.
7. WYSIWYG, (What yuo see is what you get), artinya saaat melakukan pencetakan tidak ada perbedaan antara yang dilihat pengguna dengan outputnya.

8. Aesthic integrity, artinya informasi diorganisasi dengan baik dan konsisten dengan prinsip perancangn visual yang baik.

Sedangkan contex diagram untuk program perangkat perangkat lunak antar muka untuk inisialisasi dan tampilan data parameter penampilan cuaca dapat dilihat pada gambar 3.2 berikut:

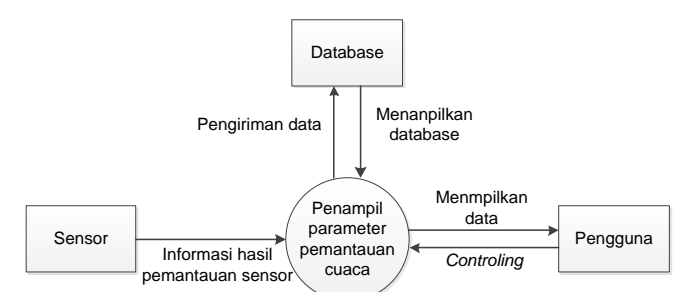

Gambar 3.2 Contex Diagram untuk Program Inisialisasi dan Tampilan Data untuk Parameter Pemantau Cuaca

Untuk memperjelas contex diagram, maka dibuat turunan atau jabaran dari contex diagram yaitu data flow diagram (DFD). DFD ini menggambarkan data, aliran data dan laporan yang dihasilkan. Gambar 3.3 merupakan DFD dari perancangan program perangkat lunak inisialisasi dan tampilan data parameter pemantau cuaca.

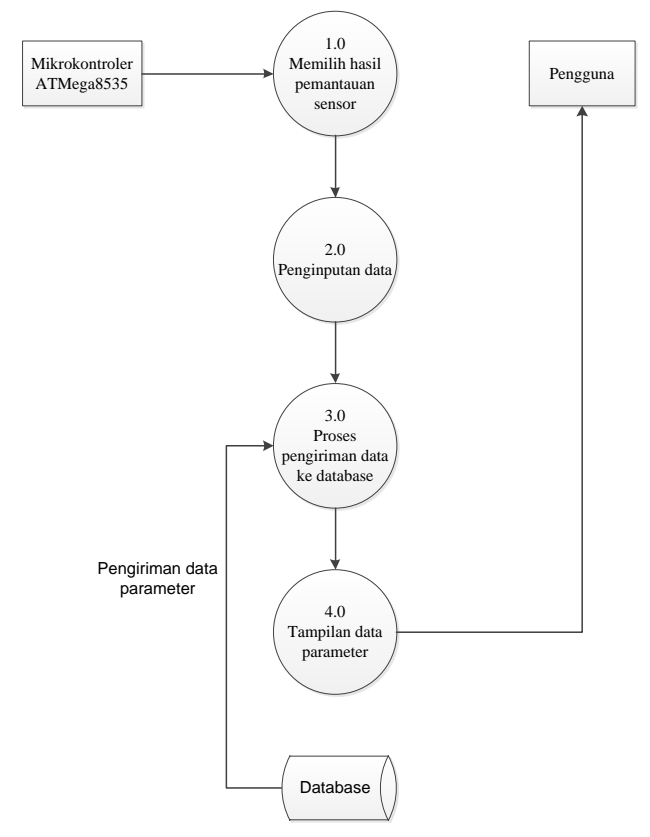

Gambar 3.3 Data Flow Diagram untuk Inisialisasi dan Tampilan Data untuk Parameter Pemantau Cuaca

Perancangan Peket Data 
Berikut adalah paket data yang dikirimkan melalui antar muka komunikasi serial RS232

Tabel 3.1 Keterangan chanel

\begin{tabular}{|c|l|}
\hline Paket Data & \multicolumn{1}{c|}{ Keterangan } \\
\hline $\mathrm{CH} 1$ & $\begin{array}{l}\text { Nama yang digunakan untuk } \\
\text { menerima hasil akuisisi data dari } \\
\text { sensor suhu. }\end{array}$ \\
\hline $\mathrm{CH} 2$ & $\begin{array}{l}\text { Nama yang digunakan untuk } \\
\text { menerima hasil akuisisi data dari } \\
\text { sensor arah angin. }\end{array}$ \\
\hline $\mathrm{CH} 3$ & $\begin{array}{l}\text { Nama yang digunakan untuk } \\
\text { menerima hasil akuisisi data yang } \\
\text { diperoleh dari sensor kecepatan } \\
\text { angin. }\end{array}$ \\
\hline
\end{tabular}

dimana CH1 100.00 C CH2 360.00 LU CH3 110.00 MPH dan keterangannya dapat dilihat pada tabel dibawah ini:

Tabel 3.2 Keterangan hasil akuisisi data

\begin{tabular}{|c|l|}
\hline Paket Data & \multicolumn{1}{c|}{ Keterangan } \\
\hline 100.00 & $\begin{array}{l}\text { Nilai maksimal dari parameter } \\
\text { suhu }\end{array}$ \\
\hline 360.00 & $\begin{array}{l}\text { Nilai maksimal dari parameter } \\
\text { arah angin }\end{array}$ \\
\hline 110.00 & $\begin{array}{l}\text { Nilai maksimal dari parameter } \\
\text { kecepatan angin }\end{array}$ \\
\hline
\end{tabular}

Tabel 3.3 Satuan

\begin{tabular}{|c|l|}
\hline Paket Data & \multicolumn{1}{c|}{ Keterangan } \\
\hline C & $\begin{array}{l}\text { Celsius, merupakan satuan dalam } \\
\text { menentukan derajat suhu }\end{array}$ \\
\hline LU & $\begin{array}{l}\text { Lintang Utara, merupakan garis } \\
\text { khayal yang digunkan untuk } \\
\text { menentukan lokasi/arah terhadap } \\
\text { garis katulistiwa }\end{array}$ \\
\hline MPH & $\begin{array}{l}\text { Mile Per Hour, merupakan satuan } \\
\text { dalam menentukan kecepatan. }\end{array}$ \\
\hline
\end{tabular}

Data hasil keluaran RS232 masuk ke komputer melalui port serial, yang kemudian akan diolah dengan menggunakan program Visual Basic 6.0.

\section{IMPLEMENTASI DAN ANALISA}

\section{Perancangan Aplikasi Penampil}

Parameter Cuaca Berbasis Personal Computer

Implementasi Interaksi aplikasi yang dirancang dengan Visual Basic 6.0 dapat memudahkan user untuk menggunakan aplikasi ini. Tampilan dan penggunaan yang mudah, menjadikan Visual Basic 6.0 software untuk perancangan aplikasi ini. Adapun beberapa tampilan dari aplikasi yang dirancang untuk berinteraksi dengan pemakai diantaranya:

\section{Tampilan Form Awal}

Aplikasi ini memiliki beberapa menu yang terhubung pada form lain yaitu dalam bentuk menu edit, dimana dari form satu ke form yang lain dapat terhubung secara otomatis. Adapun untuk tampilan utama pada Form Awal yang telah dirancang memiliki menumenu yang tersedia sebagai informasi untuk melihat fasilitas apa saja yang disediakan pada aplikasi tersebut. Adapun tampilan dari form awal dapat dilihat pada gamabr 4.1 di bawah ini.

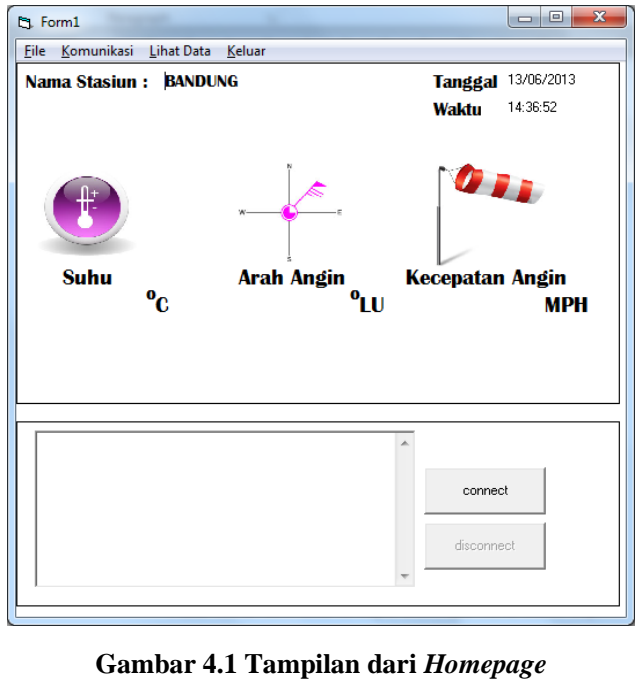

Pada menu form awal terdapat beberapa menu editor seperti "File", "Komunikasi", "Lihat Data" dan "Keluar" yang masing masing memiliki fungsi yang berbeda. Apabila menu editor "komunikasi" ditekan maka akan muncul sub menu "setting" dan bila sub menu "setting" ini ditekan maka form akan pindah ke form setingan port seperti gambar 4.2 di bawah ini.

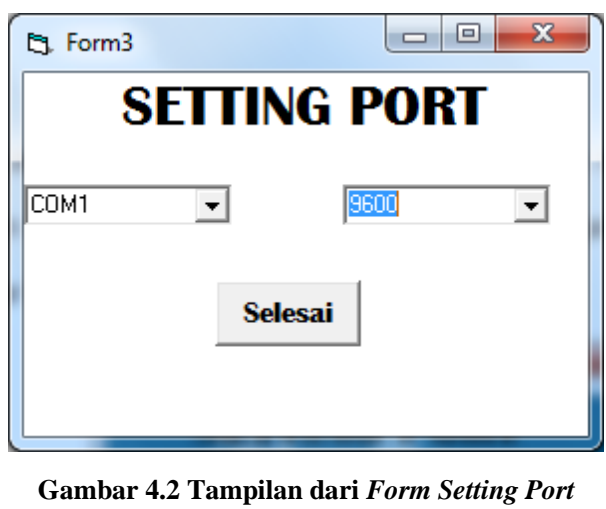


Dalam menu setting port user dapat memilih port mana saja yang terkoneksi dengan RS232 kemudian user memilih baud rate yang digunakan. Setelah user memilih keduanya user menekan tombol selesai.

Selain menu editor terdapat dua command button "connect" dan "disconnect". Fungsi dari command button connect adalah untuk mengaktifkan alat pendetektor suhu dan menampilkan data yang telah di deteksi oleh alat pendetektor kedalam aplikasi ini, apabila settingan port tidak benar maka sistem akan menampilkan peringatan berupa message box seperti gambar 4.3 di bawah ini.

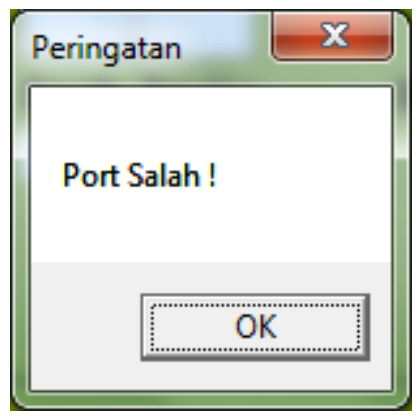

Gambar 4.3 Tampilan Peringatan Apabila Port Salah

Dalam peringatan tersebut terdapat tombol "OK" yang berfungsi untuk kembali ke menu form setting port yang selanjutnya user memilih kembali port dan baud rate yang digunakan. Apabila setingan port benar sistem secara otomatis akan menapilkan data yang diambil dari alat pendetektor seperti gambar 4.4 di bawah ini.

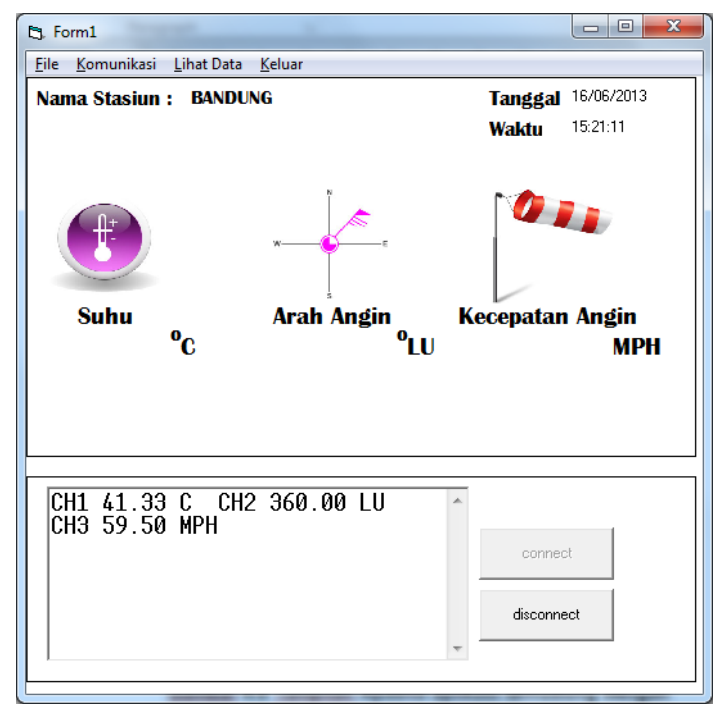

Gambar 4.4 Tampilan Apabila Aplikasi Terhubung dengan RS232
Adapun setting komunikasi yang digunakan menggunakan COM1, baud rate = $9600 \mathrm{Kpbs}$. Setelah data diterima oleh sistem maka sistem secara otomatis memisahkan dan memindahkan data ke masing masing parameter yang telah disediakan, seperti gambar 4.5 berikut.

Bila data telah dimasukan ke masing masing parameter, sistem secara otomatis menyimpan data tersebut kedalam database. Untuk melihat hasil penyimpanan data, user memilih menu editor "lihat data" dan memilih sub menu "buka list".

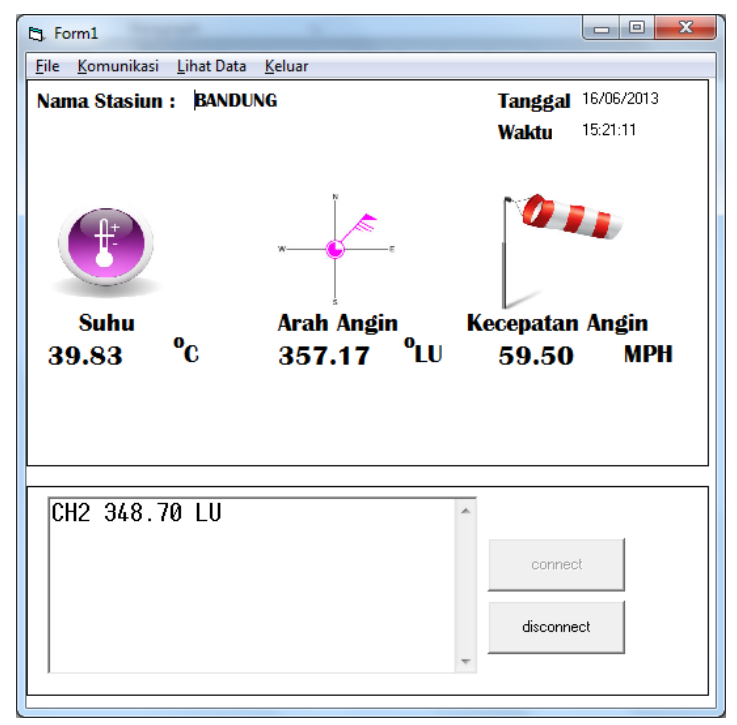

Gambar 4.5 Tampilan Pemindahan Data ke Masing Masing Parameter

Dalam menu editor "buka list" dapat terlihat seluruh data yang telah disimpan seperti pada gambar 4.6 di bawah ini.

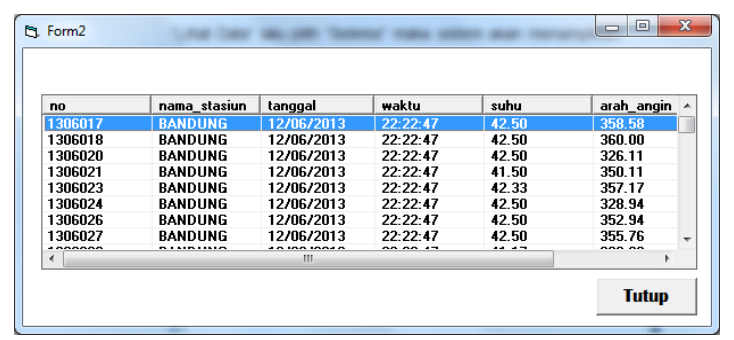

Gambar 4.6 Tampilan List Data

\section{Tabel Seleksi}

Untuk menampilkan tabel seleksi user cukup memilih menu "Lihat Data" lalu pilih "Seleksi" maka sistem akan menampilkan form seleksi separti gambar 4.7 berikut. 


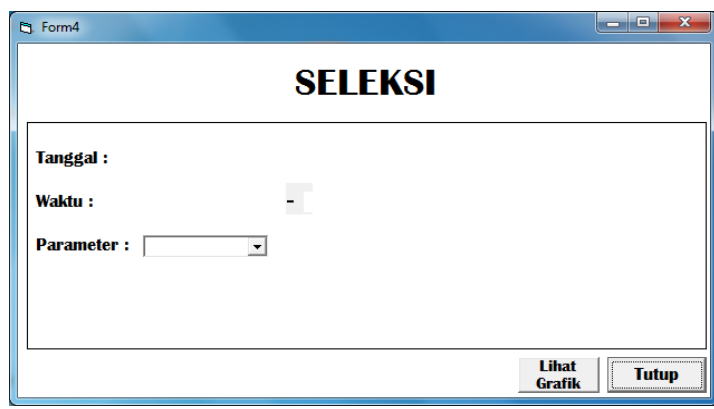

Gambar 4.7 Tampilan Form Seleksi

Dalam form seleksi user memilih tanggal, waktu awal dan waktu akhir serta nama parameter untuk memunculkan hasil pencarian. Apabila data yang di inputkan benar maka sistem akan menampilkannya dalam bentuk tabel seperti gambar 4.8 berikut.

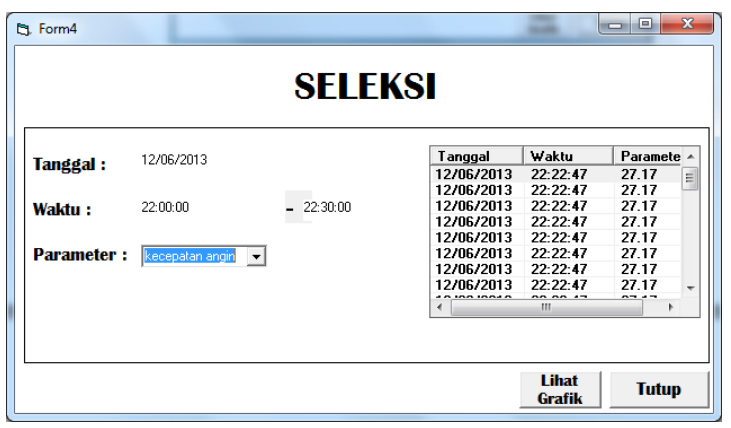

Gambar 4.8 Hasil Seleksi

Kemudian user dapat menampilkan hasil pencarian tersebut berupa grafik batang dengan menekan tombol lihat grafik, gambar 4.9 merupakan tampilan grafik hasil pencarian.

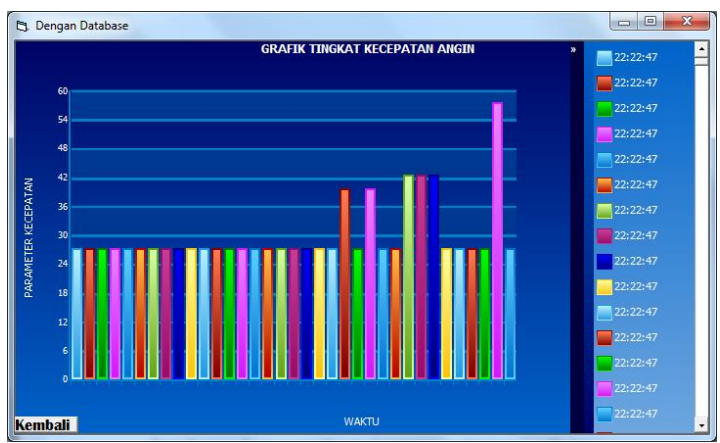

Gambar 4.9 Tampilan Grafik Hasil Pencarian

User dapat mengakhiri aplikasi ini dengan memilih menu editor "keluar", sistem akan memunculkan informasi berupa mesage box untuk mengakhiri aplikasi ini seperti gambar 4.10 dibawah ini.

Apabila user memilih tombol "yes" maka sistem secara otomatis akan berakhir, apabila user memilih tombol "no" maka sistem akan menampilkan kembali menu sebelumnya.

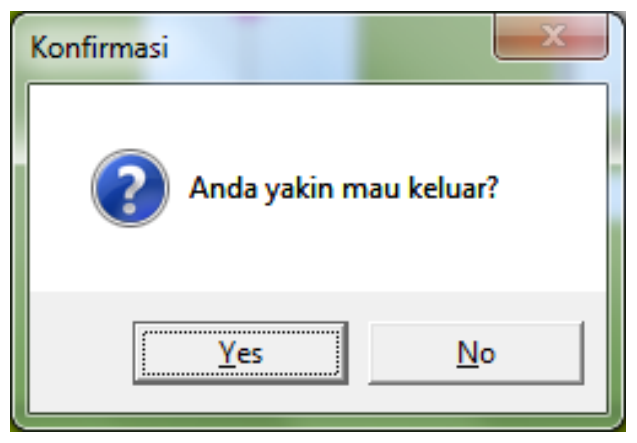

Gambar 4.10 Tampilan Konfirmasi

\section{KESIMPULAN DAN POTENSI PENGEMBANGAN}

\section{Kesimpulan}

1. Pembuatan program aplikasi Rancang Bangun Penampil Parameter Cuaca berbasis Personal Computer untuk Stasiun Cuaca Mini ini, antara Mikrokonteroler AVR ATMega8535 sebagai pengirim informasi cuaca dan Personal Computer sebagai penampil informasi cuaca dapat derealisasikan dan disimpan dalam sebuah database.

2. Dengan menggunakan komunikasi serial RS232 maka data-data dari hasil pemantauan dapat diterima.

\section{Potensi Pengembangan}

Dalam bagian ini penulis mencoba untuk memberikan saran-saran yang mungkin dapat dipertimbangkan dalam memanfaatkan aplikasi yang penulis buat, yaitu:

1. Dalam segi tampilan aplikasi untuk kedepanya lebih dikembangkan agar tampilan lebih menarik dan mudah dipahami oleh user.

2. Dalam segi penyimpanan data menggunakan database yang dapat lebih banyak menyimpan data.

\section{DAFTAR PUSTAKA}

[1] http://www.scribd.com/doc/18271343/6/Pe ngertian-Umum-Sensor

[2] Putra, Agfianto Eko dan Nugraha, Dhani, 2011, Tutorial Pemograman Mikrokontroler AVR dengan AVR Studio dan WinAVR GCC (ATMega16/32/8535), Yogyakarta : Universitas Gajah Mada. 
[3] http://www.google.com/url?sa=t\&rct=j\&q $=\&$ esrc $=\mathrm{s} \&$ source $=\mathrm{web} \& \mathrm{~cd}=2 \& \mathrm{cad}=\mathrm{rja} \&$ ved $=0 \mathrm{CDcQFj} A B \&$ url $=\mathrm{http} \% 3 \mathrm{~A} \% 2 \mathrm{~F} \% 2 \mathrm{~F}$ repository.usu.ac.id\%2Fbitstream\%2F123 456789\%2F19903\%2F4\%2FChapter\%252 0II.pdf\&ei=SyqGUYmnLMrYrQefpIDgC Q\&usg=AFQjCNF4i0_orS6v_uU8-eVAL17c8kyKA\&bvm=bv.45960087, d.bmk. Diakses pada 5 Mei 2013.

[4] http://1.bp.blogspot.com/HOpK3TgOSwA /Tn6yUfhckiI/AAAAAAAAABI/sJRDOO5LGw/s1600/sistem+flowchart.jpg. Diakses pada 16 Mei 2013 